\title{
Thermal and elastic properties of $\mathrm{Cu}-\mathrm{Zr}$-Be bulk metallic glass forming alloys
}

\author{
Gang Duan, ${ }^{a)}$ Mary Laura Lind, Katrien De Blauwe, Aaron Wiest, and William L. Johnson \\ W.M. Keck Laboratory of Engineering Materials, mail code 138-78, California Institute of Technology, \\ Pasadena, California 91125
}

(Received 22 February 2007; accepted 25 April 2007; published online 21 May 2007)

\begin{abstract}
The compositional dependence of thermal and elastic properties of $\mathrm{Cu}-\mathrm{Zr}-\mathrm{Be}$ ternary bulk metallic glass forming alloys was systematically studied. There exists a linear relationship between the glass transition temperature $T_{g}$ and the total $\mathrm{Zr}$ concentration. $G$ decreases linearly with increasing $\mathrm{Zr}$ concentration as well. The results also show that $T_{g}$, shear modulus $G$, and Poisson's ratio $\nu$ are very sensitive to changes in compositions. Low $T_{g}$, low $G$, and relatively high $\nu$ can be achieved with high $\mathrm{Zr}$ and Ti concentration. (C) 2007 American Institute of Physics.
\end{abstract}

[DOI: $10.1063 / 1.2741050$ ]

Bulk metallic glasses (BMGs) have acquired significant attention from scientific and technological view points in the past 20 years. ${ }^{1,2}$ BMGs usually show high strength, high specific strength, large elastic strain limit, and excellent wear and corrosion resistances along with other remarkable engineering properties. Researchers have developed families of binary and multicomponent systems ${ }^{3-11}$ to form BMGs, among which Zr-based Be-bearing BMGs (Vitreloy series) ${ }^{3}$ have been utilized commercially to produce items including sporting goods and electronic casings.

The glass forming ability (GFA), and rheological and mechanical properties of different alloy systems have been extensively studied. Previous literature indicates that highly processable Vitreloy BMGs tend to show rather strong liquid behaviors. ${ }^{12-14}$ Recently, it was discovered that $\mathrm{Cu}-\mathrm{Zr}$ binary alloys, ${ }^{7,10,15}$ which can be cast into bulk amorphous structures with sample diameters up to $2 \mathrm{~mm}$, show relatively fragile behaviors in viscosity. ${ }^{16}$ Therefore, it is believed that there exists a balance point between GFA and fragility, which can be utilized to design novel bulk amorphous alloy systems.

There is plenty of evidence to show that the ductile behavior of BMGs is closely related to their Poisson's ratio. ${ }^{17}$ For instance, the Pt-based BMG (Ref. 18) with high Poisson's ratio of $\sim 0.41$ shows excellent compressive ductility and high fracture toughness, while the Fe-based BMG with low Poisson's ratio of $\sim 0.30$ (Ref. 19) shows poor ductility and low fracture toughness. It was also reported that the critical Poisson's ratio ${ }^{19}$ for compressive plasticity in $\mathrm{Fe}-$ Mo-C-B-Ln BMGs is about 0.32, where an onset of plasticity was observed. Novikov and Sokolov ${ }^{20,21}$ found that Poisson's ratio of a glass at room temperature correlated well with the fragility of glass forming liquids at high temperature. In an effort to further understand the relationship among Possion's ratio, fragility, and GFA, we report in this letter, the compositional dependence of thermal and elastic properties in $\mathrm{Cu}-\mathrm{Zr}-\mathrm{Be}$ bulk metallic glass forming alloys.

Conner and Johnson reported ${ }^{22}$ that the bending ductility of amorphous alloys in the $\mathrm{Zr}-\mathrm{Ti}-\mathrm{Ni}-\mathrm{Cu}-\mathrm{Be}$ system is composition dependent. Alloys with a higher Zr:Ti ratio show

\footnotetext{
a) Author to whom correspondence should be addressed; electronic mail: duan@caltech.edu.
}

better ductility over a wide range of compositions than those with a lower Zr:Ti ratio. It is empirically known as well that $\mathrm{Ni}$ rather makes the glass forming liquid stronger thus resulting in better GFA. Therefore, by eliminating $\mathrm{Ni}$ and $\mathrm{Ti}$ from Vitreloy series, we carried out systematic studies on bulk glass formation, and thermal and elastic properties in the $\mathrm{Cu}-\mathrm{Zr}-\mathrm{Be}$ alloy system. According to our design, it is believed that the $\mathrm{Cu}-\mathrm{Zr}-\mathrm{Be}$ glassy alloys have higher Poisson's ratio and lower shear modulus, while maintaining the good processability of Be-bearing BMGs.

Mixtures of elements of purity ranging from $99.9 \%$ to 99.99\% were alloyed by induction melting on a water cooled silver boat or arc melting under a Ti-gettered argon atmosphere. Ingots of typical size of $10 \mathrm{~g}$ were prepared. Each ingot was flipped over and remelted at least three times in order to obtain chemical homogeneity. The ingots then were remelted under high vacuum in a quartz tube using an induction heating coil and injected through an $\sim 0.5-1 \mathrm{~mm}$ (inner diameter) nozzle into copper molds using high-purity argon at a pressure of $\sim 1-2 \mathrm{~atm}$. These copper molds have internal cylindrical cavities of diameters ranging from 1 to $10 \mathrm{~mm}$. A Philips X'Pert Pro x-ray diffractometer and a Netzsch 404C differential scanning calorimeter (performed at a constant heating rate $0.33 \mathrm{~K} / \mathrm{s}$ ) were utilized to confirm the amorphous nature and to examine the thermal behaviors of these cast samples. The pulse-echo overlap technique with $25 \mathrm{MHz}$ piezoelectric transducers was used to measure the shear and longitudinal wave speeds at room temperature for each of the samples. Sample density was measured by the Archimedean technique according to the American Society of Testing Materials standard C 693-93. To get rid of any possibility of cooling effect on the elastic properties, ${ }^{23-25}$ we carried out the measurements on $2.5 \mathrm{~mm}$ cast strip samples for all the alloys studied in this letter.

The glass forming ability in the $\mathrm{Cu}-\mathrm{Zr}-\mathrm{Be}$ ternary alloy system was systematically studied. Considering that the total $\mathrm{Zr}$ and $\mathrm{Ti}$ concentration in Vitreloy 1 is $55 \%$, the $\mathrm{Zr}$ content in $\mathrm{Cu}-\mathrm{Zr}-\mathrm{Be}$ alloys studied was chosen to range from $50 \%$ to $65 \%$, while the Be varies from $16 \%$ to $30 \%$. Figure 1 shows bulk glass formation diagram in this ternary system. The amorphous nature of all the samples studied in this work has been confirmed by $\mathrm{x}$-ray diffraction and thermal analysis. The best GFA region is found when the $\mathrm{Zr}$ concentration is 


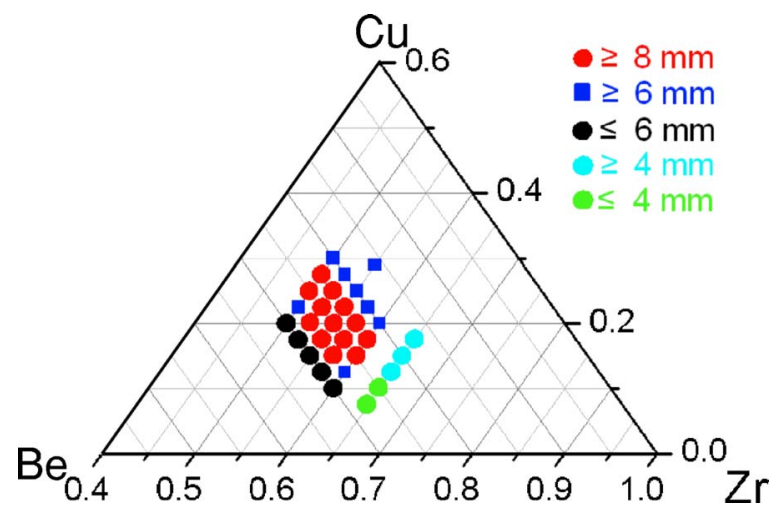

FIG. 1. (Color online) Bulk metallic glass formation map in the $\mathrm{Cu}-\mathrm{Zr}-\mathrm{Be}$ ternary alloy system.

between $50 \%$ and $60 \%$. The alloys can be cast into fully amorphous rods of diameter at least $8 \mathrm{~mm}$ provided that $\mathrm{Be}$ is between $22.5 \%$ and $27.5 \%$. When Be is reduced to less than $20 \%$, $6 \mathrm{~mm}$ fully amorphous rods could still be obtained by copper mold casting. However, once Be is greater than $30 \%$, the GFA is observed to decrease to below $6 \mathrm{~mm}$. If $\mathrm{Zr}$ is increased to be $65 \%$ in the $\mathrm{Cu}-\mathrm{Zr}-\mathrm{Be}$ ternary system, the casting diameter of fully amorphous rods is limited to about $4 \mathrm{~mm}$ or below.

A summary of the thermal and elastic properties of the representative glassy alloys in the $\mathrm{Cu}-\mathrm{Zr}-\mathrm{Be}$ ternary system and Vitreloy-type BMGs (Refs. 26 and 27) is listed in Table I. The variations of supercooled liquid region $\Delta T$ ( $\Delta T=T_{x}-T_{g}$, in which $T_{x}$ is the onset temperature of the first crystallization event and $T_{g}$ is the glass transition temperature) and reduced glass transition temperature $T_{\mathrm{rg}}\left(T_{\mathrm{rg}}\right.$ $=T_{g} / T_{l}$, where $T_{l}$ is the liquidus temperature) are calculated. It is clearly seen from Table I that $T_{\mathrm{rg}}$ follows a decreasing trend with increasing $\mathrm{Zr}$ concentration in $\mathrm{Cu}-\mathrm{Zr}-\mathrm{Be}$ ternary system, which is consistent with Fig. 1. We also note that all the ternary alloys show very good thermal stability. For example, $\mathrm{Zr}_{55} \mathrm{Cu}_{20} \mathrm{Be}_{25}, \mathrm{Zr}_{57.5} \mathrm{Cu}_{17.5} \mathrm{Be}_{25}$, and $\mathrm{Zr}_{60} \mathrm{Cu}_{17.5} \mathrm{Be}_{22.5}$ show large supercooled liquid regions of over $100 \mathrm{~K}$. When compared to Vitreloy 1 and Vitreloy 4, $\mathrm{Cu}-\mathrm{Zr}-\mathrm{Be}$ ternary alloys are designed to have higher Poisson's ratios and lower shear moduli by removing $\mathrm{Ni}$ and $\mathrm{Ti}$ and sacrificing some of the GFA.

The glass transition temperatures of $\mathrm{Cu}-\mathrm{Zr}-\mathrm{Be}$ ternary alloys and Vitreloy-type alloys as a function of the total concentration of $\mathrm{Zr}$ and Ti are plotted in Fig. 2. It is noticed that there exists a linear relationship between $T_{g}$ and $\mathrm{Zr}(\mathrm{Ti})$ con-

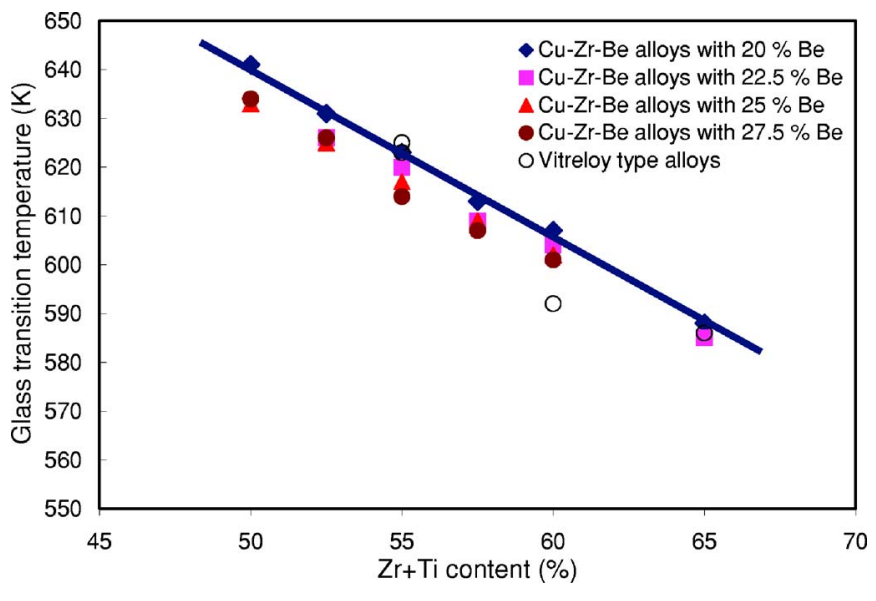

FIG. 2. (Color online) Glass transition temperature as a function of the total $\mathrm{Zr}$ and $\mathrm{Ti}$ content in $\mathrm{Cu}-\mathrm{Zr}-\mathrm{Be}$ ternary and Vitreloy-type bulk metallic glasses.

centration. Small variations may occur depending on the Be content. $T_{g}$ is high at low $\mathrm{Zr}(\mathrm{Ti})$ concentrations $(640 \mathrm{~K}$ for $\left.\mathrm{Zr}_{50} \mathrm{Cu}_{30} \mathrm{Be}_{20}\right)$, decreasing to $607 \mathrm{~K}\left(\mathrm{Zr}_{60} \mathrm{Cu}_{20} \mathrm{Be}_{20}\right)$ and to $588 \mathrm{~K}$ as $\mathrm{Zr}(\mathrm{Ti})$ content increases to $65 \%\left(\mathrm{Zr}_{65} \mathrm{Cu}_{15} \mathrm{Be}_{20}\right)$. The slope was measured to be $-3.5 \mathrm{~K}$ per $1 \%$ change in $\mathrm{Zr}(\mathrm{Ti})$ concentration. We also note that $\mathrm{Zr}_{65} \mathrm{Cu}_{12.5} \mathrm{Be}_{22.5}$ shows a $T_{g}$ of $585 \mathrm{~K}$, which is $38 \mathrm{~K}$ lower than that of Vitreloy 1 .

We present the shear modulus $G$ as a function of $\operatorname{Zr}(\mathrm{Ti})$ concentration and the Poisson's ratio $\nu$ as a function of $\mathrm{Zr}(\mathrm{Ti})$ concentration in Figs. 3 and 4, respectively. It is shown that both $G$ and $\nu$ are very sensitive to changes in composition. $\mathrm{Zr}_{50} \mathrm{Cu}_{30} \mathrm{Be}_{20}$ exhibits a high $G$ of $36.4 \mathrm{GPa}$, and increasing $\mathrm{Zr}$ in $\mathrm{Cu}-\mathrm{Zr}-\mathrm{Be}$ alloys decreases $G$, which drops to $27.3 \mathrm{GPa}$ for $\mathrm{Zr}_{65} \mathrm{Cu}_{15} \mathrm{Be}_{20}$. The line in Fig. 3 represents the best linear fit to the data obtained from $\mathrm{Cu}-\mathrm{Zr}-\mathrm{Be}$ alloys with Be concentration of $20 \%$. The slope was measured to be $-0.6 \mathrm{GPa}$ per $1 \%$ change in $\mathrm{Zr}$ content. As indicated in Table I, the bulk modulus $B$ of all the $\mathrm{Cu}-\mathrm{Zr}-\mathrm{Be}$ ternary alloys and Vitreloy series does not change much and remains nearly constant at $\sim 110 \mathrm{GPa}$. The open circles in Figs. 3 and 4 depict the effects of $\mathrm{Ni}$ and $\mathrm{Ti}$ on $\mathrm{G}$ as well as on $\nu$ for Vitreloy-type alloys. Apparently, designing novel BMGs with high Poisson's ratios and lower shear moduli by removing $\mathrm{Ni}$ and $\mathrm{Ti}$ is confirmed since $\mathrm{Ni}$ and $\mathrm{Ti}$ increase $G$ remarkably and therefore reduce $\nu$. The highest $\nu$ that we can achieve from $\mathrm{Cu}-\mathrm{Zr}-\mathrm{Be}$ ternary alloys is 0.386 for $\mathrm{Zr}_{65} \mathrm{Cu}_{12.5} \mathrm{Be}_{22.5}$, which has a $G$ of $27.5 \mathrm{GPa}$.

TABLE I. Thermal and elastic properties of representative $\mathrm{Cu}-\mathrm{Zr}-\mathrm{Be}$ and Vitreloy-type glassy alloys.

\begin{tabular}{lccccccccc}
\hline \hline \multicolumn{1}{c}{ Materials } & $\begin{array}{c}T_{g} \\
(\mathrm{~K})\end{array}$ & $\begin{array}{c}T_{x} \\
(\mathrm{~K})\end{array}$ & $\begin{array}{c}T_{l} \\
(\mathrm{~K})\end{array}$ & $\begin{array}{c}\Delta T \\
(\mathrm{~K})\end{array}$ & $T_{g} / T_{l}$ & $\begin{array}{c}G \\
(\mathrm{GPa})\end{array}$ & $\begin{array}{c}B \\
(\mathrm{GPa})\end{array}$ & $\begin{array}{c}Y \\
(\mathrm{GPa})\end{array}$ & $\nu$ \\
\hline $\mathrm{Zr}_{50} \mathrm{Cu}_{25} \mathrm{Be}_{25}$ & 633 & 721 & 1140 & 88 & 0.555 & 35.8 & 108.9 & 96.8 & 0.35 \\
$\mathrm{Zr}_{52.5} \mathrm{Cu}_{22.5} \mathrm{Be}_{25}$ & 625 & 715 & 1124 & 90 & 0.556 & 35.0 & 111.5 & 92.0 & 0.36 \\
$\mathrm{Zr}_{55} \mathrm{Cu}_{20} \mathrm{Be}_{25}$ & 617 & 720 & 1122 & 103 & 0.550 & 33.7 & 108.1 & 91.6 & 0.36 \\
$\mathrm{Zr}_{57.5} \mathrm{Cu}_{17.5} \mathrm{Be}_{25}$ & 609 & 715 & 1109 & 106 & 0.549 & 31.5 & 105.1 & 85.9 & 0.36 \\
$\mathrm{Zr}_{60} \mathrm{Cu}_{17.5} \mathrm{Be}_{22.5}$ & 604 & 707 & 1110 & 103 & 0.544 & 31.9 & 111.2 & 87.3 & 0.37 \\
$\mathrm{Zr}_{65} \mathrm{Cu}_{12.5} \mathrm{Be}_{22.5}$ & 585 & 684 & 1098 & 99 & 0.533 & 27.5 & 111.9 & 76.3 & 0.39 \\
$\mathrm{Zr}_{51} \mathrm{Ti}_{9} \mathrm{Cu}_{15} \mathrm{Be}_{25}$ & 592 & $\cdots$ & 1047 & $\cdots$ & 0.565 & 31.8 & 104.3 & 86.5 & 0.36 \\
$\mathrm{Zr}_{54} \mathrm{Ti}_{11} \mathrm{Cu}_{12.5} \mathrm{Be}_{22.5}$ & 586 & $\cdots$ & 1035 & $\cdots$ & 0.566 & 30.3 & 103.5 & 82.8 & 0.37 \\
$\mathrm{Zr}_{41.2} \mathrm{Ti}_{13.8} \mathrm{Ni}_{10} \mathrm{Cu}_{12.5} \mathrm{Be}_{22.5}$ & 623 & 712 & 993 & 89 & 0.627 & 37.4 & 115.9 & 101.3 & 0.35 \\
$\mathrm{Zr}_{46.75} \mathrm{Ti}_{8.25} \mathrm{Ni}_{10} \mathrm{Cu}_{7.5} \mathrm{Be}_{27.5}$ & 625 & 738 & 1185 & 113 & 0.527 & 35.0 & 110.3 & 95.0 & 0.36 \\
\hline
\end{tabular}




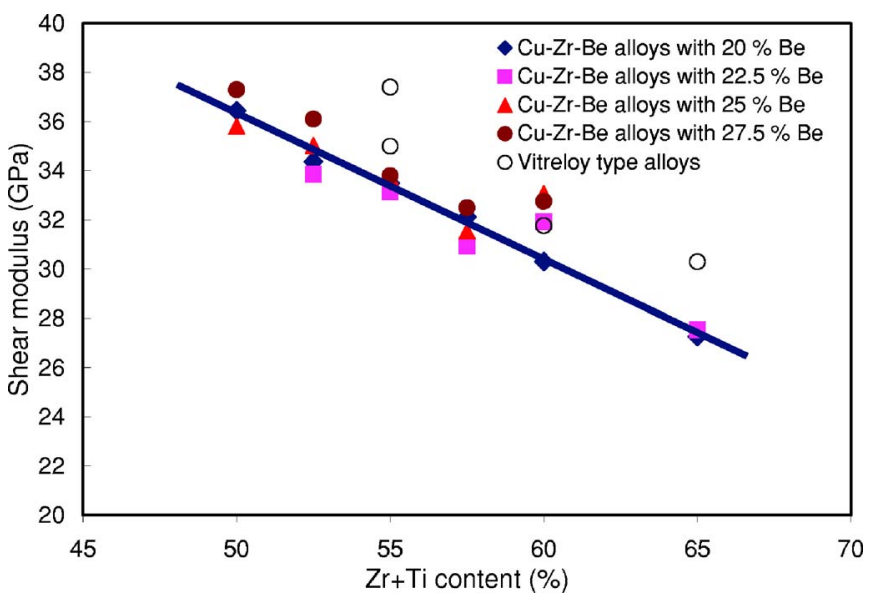

FIG. 3. (Color online) Shear modulus G vs. the total concentration of zirconium and titanium in $\mathrm{Cu}-\mathrm{Zr}-\mathrm{Be}$ ternary glassy alloys and Vitreloy-type bulk glassy alloys.

Recently, a cooperative shear model has been developed for the glassy state based on potential energy landscape/ inherent state theory to describe the yielding behavior in metallic glasses. ${ }^{26} \mathrm{~A}$ scaling relationship among the shear flow barrier, a universal critical yield strain, and the isoconfigurational shear modulus $G$ was constructed. The model reveals that for a fixed glass configuration the barrier height for shear flow is proportional to the isoconfigurational shear modulus $G$, which makes $G$ of great importance to fully understand the mechanical behaviors of BMGs and to design novel BMGs. In the $\mathrm{Cu}-\mathrm{Zr}-\mathrm{Be}$ ternary system, the bulk modulus $B$ remains almost constant. Therefore, lower $G$ implies higher Poisson's ratio and means that the shear flow barrier for an

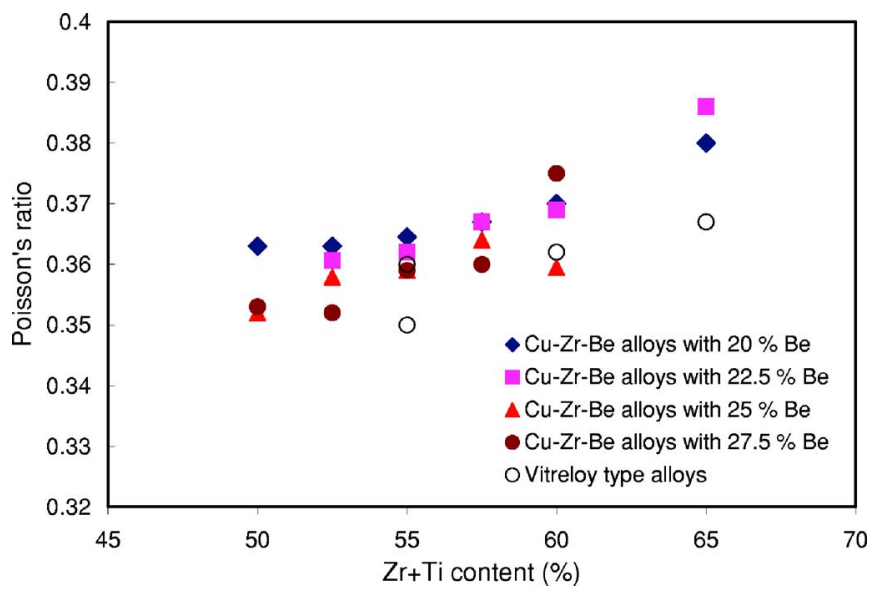

FIG. 4. (Color online) Poisson's ratio as a function of the total $\mathrm{Zr}$ and $\mathrm{Ti}$ concentration in $\mathrm{Cu}-\mathrm{Zr}-\mathrm{Be}$ ternary glassy alloys and Vitreloy-type bulk amorphous alloys. unstressed shear cooperative zone is relatively small. This allows the atoms to get into a higher potential energy configuration, which would benefit the yielding behaviors. ${ }^{23}$

In summary, we designed a class of $\mathrm{Cu}-\mathrm{Zr}-\mathrm{Be}$ BMGs with rather high Possion's ratios compared to Vitreloy series by removing $\mathrm{Ni}$ and $\mathrm{Ti}$. The compositional dependence of thermal and elastic properties was systematically studied. The results show that $T_{g}, G$, and $\nu$ are very sensitive to changes in compositions. Low $T_{g}$, low $G$, and relatively high $\nu$ can be achieved with high $\operatorname{Zr}(\mathrm{Ti})$ concentration, which helps to design bulk glassy alloys and composites.

The authors acknowledge the support from the MRSEC Program (Center for the Science and Engineering Materials, CSEM) of the National Science Foundation under Award No. DMR-0520565.

${ }^{1}$ W. L. Johnson, MRS Bull. 24, 42 (1999).

${ }^{2}$ A. Inoue, Acta Mater. 48, 279 (2000).

${ }^{3}$ A. Peker and W. L. Johnson, Appl. Phys. Lett. 63, 2342 (1993).

${ }^{4}$ V. Ponnambalam, S. J. Poon, and G. J. Shiflet, J. Mater. Res. 19, 1320 (2004).

${ }^{5}$ Z. P. Lu, C. T. Liu, J. R. Thompson, and W. D. Porter, Phys. Rev. Lett. 92, 245503 (2004).

${ }^{6}$ J. Schroers and W. L. Johnson, Appl. Phys. Lett. 84, 3666 (2004).

${ }^{7}$ D. H. Xu, G. Duan, and W. L. Johnson, Phys. Rev. Lett. 92, 245504 (2004).

${ }^{8}$ D. H. Xu, G. Duan, W. L. Johnson, and C. Garland, Acta Mater. 52, 3493 (2004).

${ }^{9}$ G. Duan, D. H. Xu, and W. L. Johnson, Metall. Mater. Trans. A 36A, 455 (2005).

${ }^{10}$ G. Duan, D. H. Xu, Q. Zhang, G. Y. Zhang, T. Cagin, W. L. Johnson, and W. A. Goddard, Phys. Rev. B 71, 224208 (2005).

${ }^{11}$ D. H. Xu, B. Lohwongwatana, G. Duan, W. L. Johnson, and C. Garland, Acta Mater. 52, 2621 (2004).

${ }^{12}$ E. Bakke, R. Busch, and W. L. Johnson, Appl. Phys. Lett. 67, 3260 (1995).

${ }^{13}$ R. Busch, E. Bakke, and W. L. Johnson, Acta Mater. 46, 4725 (1998).

${ }^{14}$ T. A. Waniuk, R. Busch, A. Masuhr, and W. L. Johnson, Acta Mater. 46, 5229 (1998).

${ }^{15}$ D. C. Hofmann, G. Duan, and W. L. Johnson, Scr. Mater. 54, 1117 (2006).

${ }^{16}$ G. J. Fan, M. Freels, H. Choo, P. K. Liaw, J. J. Z. Li, W. K. Rhim, W. L. Johnson, P. Yu, and W. H. Wang, Appl. Phys. Lett. 89, 241917 (2006).

${ }^{17}$ H. S. Chen, J. T. Krause, and E. Coleman, J. Non-Cryst. Solids 18, 157 (1975).

${ }^{18}$ J. Schroers and W. L. Johnson, Phys. Rev. Lett. 93, 255506 (2004).

${ }^{19}$ X. J. Gu, A. G. McDermott, S. J. Poon, and G. J. Shiflet, Appl. Phys. Lett. 88, 211905 (2006).

${ }^{20}$ V. N. Novikov and A. P. Sokolov, Nature (London) 431, 961 (2004).

${ }^{21}$ V. N. Novikov and A. P. Sokolov, Phys. Rev. B 74, 064203 (2006).

${ }^{22}$ R. D. Conner and W. L. Johnson, Scr. Mater. 55, 645 (2006).

${ }^{23}$ G. Duan, M. L. Lind, M. D. Demetriou, W. L. Johnson, W. A. Goddard, T. Cagin, and K. Samwer, Appl. Phys. Lett. 89, 151901 (2006).

${ }^{24}$ M. L. Lind, G. Duan, and W. L. Johnson, Phys. Rev. Lett. 97, 015501 (2006).

${ }^{25}$ W. H. Jiang, F. X. Liu, Y. D. Wang, H. F. Zhang, H. Choo, and P. K. Liaw, Mater. Sci. Eng., A 430, 350 (2006).

${ }^{26}$ W. L. Johnson and K. Samwer, Phys. Rev. Lett. 95, 195501 (2005).

${ }^{27}$ W. H. Wang, J. Appl. Phys. 99, 093506 (2006). 